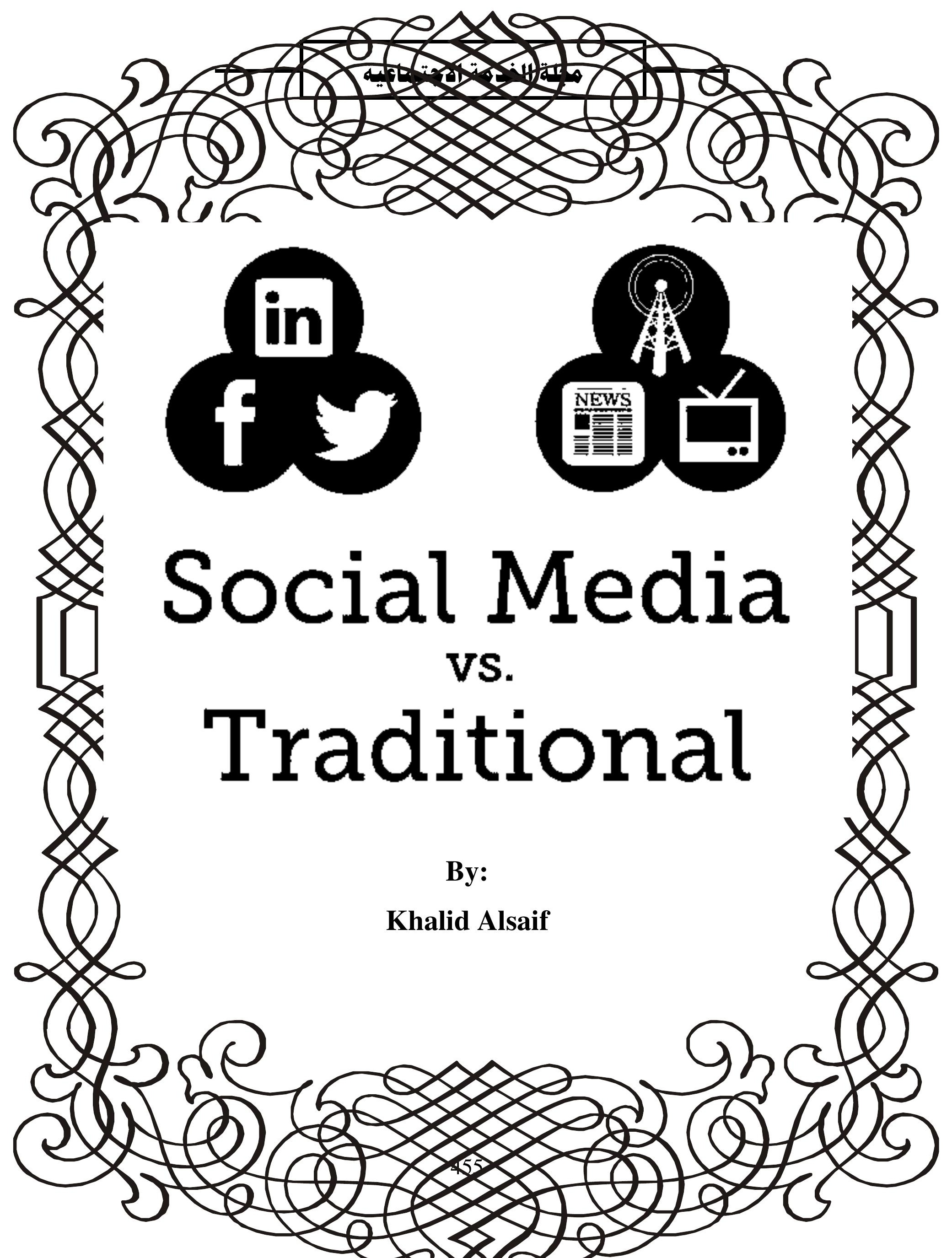


هبلة الفدهة الاجتماعية 


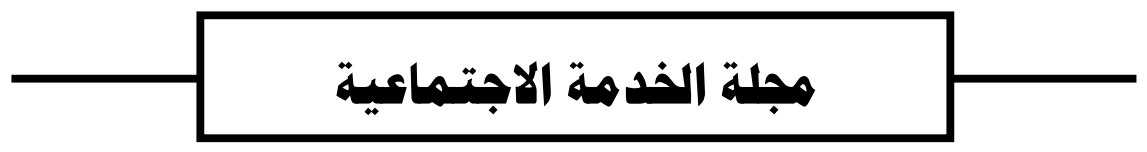

Table of Contents

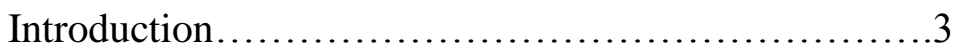

Social Media vs Traditional Media.....................5

Print Journalism \& News Media.........................12 


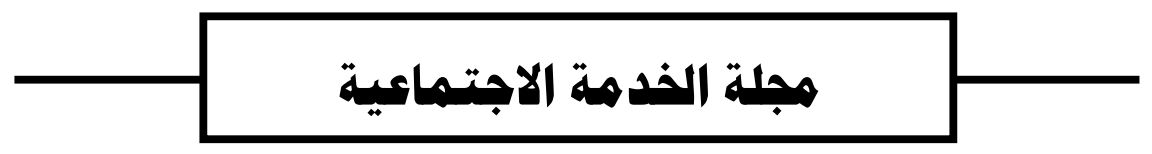

Introduction

Social media is changing the landscape of traditional media and evolving sectors of industry and aspects of society to make them more interconnected and grass roots driven. The following will assess the relationship between social media and traditional media as well as the unique ways in which Social Media has influenced news media, business, politics, and society as a whole. Both qualitative and quantitative peer reviewed data will be collected to form a clear understanding of the impact social media has had on these societal constructs. The pros and cons of current trends caused by social media will be analyzed for their true value. While social media does bring certain conflicts to the forefront like invasion of privacy, social isolation, internet censorship, and the decline of print journalism, data supports that the benefits of social media far outweigh its negative aspects. The internet has created a culture all its own. Sometimes referred to as cyberspace, cyber-culture, or simply the worldwide web, the influence of the internet can largely be seen in how the world works, human beings interact with the world and even how human beings interact with one another. The internet has established its own revolutionary form of economy in e-commerce, and redefined how individuals perceive themselves and what they consider to be human. 


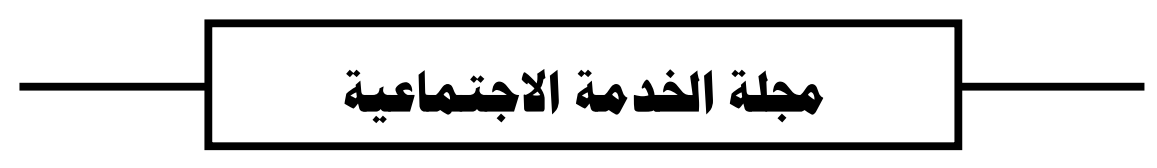

\section{Social Media Vs Traditional Media}




\section{هجلة الذذهة الاجتهاعية}

\section{Social Media vs. Traditional Media}

This section will go in depth defining the two media types, their similarities, difference and how they impact one another. Traditional media is most commonly understood as newspapers, television, radio, magazines, newsletters, tax press and a wide range of other print publications. Social media on the other hand, is recognized as the new generation of communication technologies usually composed of digital, computerized, or network information mediums. These mediums can take a variety of forms, such as wikis, podcasts, internet forums, blogs, pictures, music- and video-sharing. Examples of social media applications are Google Groups, Wikipedia, Linkedln, Facebook, YouTube, Second Life, Instagram and Twitter.

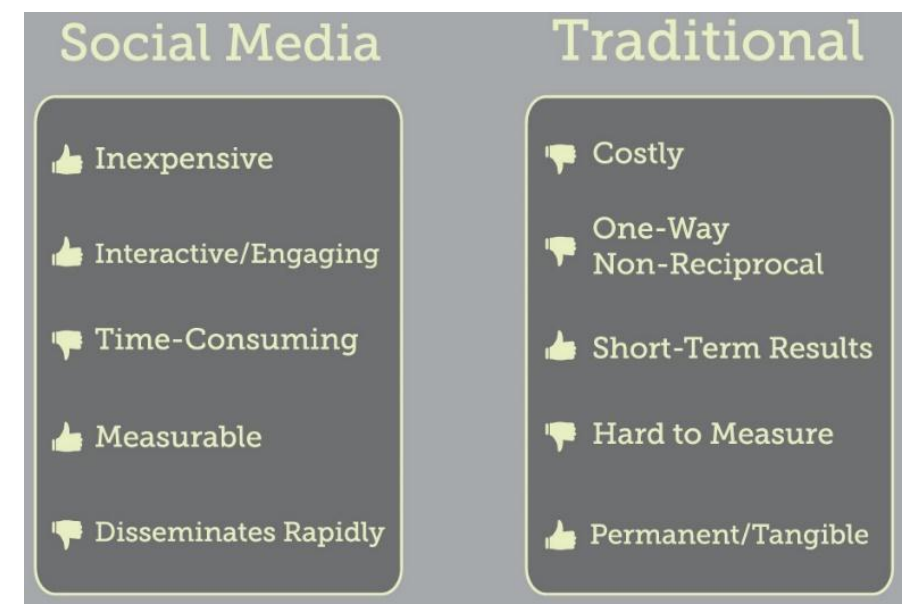

(Bennett, 1)

In Shea Beneett's MediaBistro article on the differences between social media and traditional media, she notes that social media has rapidly changed the way individuals live their daily lives mostly due to the power it gives the public to engage with one another through content, as well as their ability to interact with their favorite brands. Bennett points out some of the differences between social media marketing and traditional marketing is that social media marketing is cheaper, noting that, 'you can reach 1,000 people for a fraction of the cost using social media that you can through television, billboards or even email" (Bennett, 1). Social media is the only platform that lets businesses, politicians running for office, or even individuals promoting their on pet projects the ability to interact with fans, constituents or consumers Bennett further notes that this interaction in is a two-way relationship, that in many ways can be 


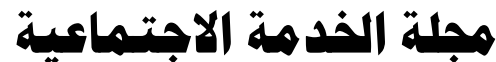

hugely lucrative for corporations or rewarding for any looking to promote their idea or concept. The most significant factor is that is of minimal cost and can be originated on a grass roots level. Another advantage that social media marketing offers over traditional media is that the results are easily measurable (Bennett, 1). Bennett does point out that the use of social media marketing campaigns are not all they are cracked up to be as the result of these campaigns can disseminate rapidly compared to the results produced by a traditional campaign. Bennett states that, "social media campaigns can be time consuming and the impact can disseminate very quickly, whereas traditional marketing campaigns, certainly in television, can produce short term results that have greater tangibility" (Bennett, 1).

Another drastic change that has evolved out of social media is the emergence of digital culture. New media encompasses the evolution and constants development of digital, computerized, or networked information and communication technologies. In Henry Jenkins publication, Convergence Culture: Where Old and New Media Collide, he makes the point that in the world of media convergence, every important story gets told, every brand gets sold, and every consumer gets courted across multiple media platforms (Jenkins, 6). This is drastically different from prior relationship individuals shared with traditional media as it was more passive form of media communication that and active form. For one to get the daily news, they simply could turn on the television or radio, and the recent gossip, or headline of the day would be plastered across the screen.

In Jenkin's novel, he points to the fact that social media has dramatically changed the landscape of how people gain information. He refers to the way individuals gather information, in this new digital age ushered in by the internet, as trans media storytelling. When explaining how transmedia storytelling works, Jenkins compares it to the act of creating a world in which the consumer must take the role of hunters and gathers to become completely familiar with all the available content on the subject. This is a much more grassroots method of receiving information, because it is essentially a form of retrieving information. Trans media storytelling is driven in the digital age by social media networks such as Twitter Facebook, and YouTube. Another conflict that is arising in the digital age is an epidemic known as the global digital divide. 
The current implications of the global digital divide and the role of developed nations to bridge the gap between nations that are less technologically advanced, is that countries where individuals have their own internet connections tend to be more informed and empowered socioeconomically. As globalization expands the reach of e-commerce and digital telecommunications in the form of mobile devices and social networks, internet use becomes an increasingly more a distinct measure of socioeconomic success and affluence worldwide. This poses a question as to what causes the technological gap between countries and what is the role of more technologically advanced nations to bridge this gap? The following research attempts to answer these questions. There has long been a dividing line between the haves and have nots, while it has largely been measured in fiscal terms, wealth is predominantly understood as a byproduct of access. On a global and international level, in his article The international gap in technology, author Potashnik notes that dawn of the twenty-first century, there was a major gap between industrialized and developing countries in terms of their access to information and communications technology" (Potashnik 1). The author goes on to identify globalization as the main cause of this discrepancy. He says, "This gap has come to be known as the digital divide and is illustrative of the vast differences in development among nations resulting from the process of globalization" (Potashnik 1). The data presented in this research article sets the groundwork for a clearer understanding of the relationship between countries as they are measured by their use of the internet and its related technologies.

The digital divide between nations is the best tool to use as a defining example of the difference between traditional media and social media, specifically in regards to how social media has impacted society. There is a consensus among researchers of technology and its world influence that the current global divide in digital technology can be measured by cross-national differences in Internet use which can be directly attributed to the economic, regulatory and sociopolitical characteristics of countries and their evolution over time (Creeber \& Martin, 5). In a recent study examining data of over 118 countries from 1997 through 2001, researchers found a massive amount of results supporting the hypothesis that, internet use increases world-system status, privatization and competition in the telecommunications, democracy and cosmopolitanism (Creeber \& Martin, 5). The discrepancies in sociopolitical characteristics shared between the countries that heavily use social media and the internet verses those that are still reliant on the traditional mediums, shed lights on the impact of this new technological wave, 
and almost gives a window into a pre-digital era. The long term influence of the global digital gap can be seen in the access to education and opportunity which social media provides nations that traditional media fails to offer on the same level.

In his work Addressing the Global Digital Divide and its Impact on Educational Opportunity Drew Tiene makes a connection between access to information and education. He theorizes that lack of information through the internet has a direct effect on access to opportunities (Tiene, 22). He largely attributes this disparity to the ample growth of educational resources found online but also some significant tools provided through the web such as online degree providing educational institutions. Likewise, social media outlets such as Twitter, YouTube, and Facebook are largely attributed to the types of social networking applications that empower citizens to be active and informed politically, to be more socially responsible, environmentally and community conscious and to invest greater interest in the political process and workings of their national government. A prime example of this can be seen with the impact social media made on a global political level with the Arab Springs movement, or the 2008 and 2012 U.S. presidential election.

In their study An initiative to Narrow the Digital Divide the authors evaluate the preliminary results of initiative implemented by the U.S. to narrow the technological gap between states as well as worldwide (Sipior, Ward \& Marzec, 1287). In the study, the authors identify the digital divide as, "a gap between those with access to new information technologies and those without. The term is also used to characterize the disparity between those who can effectively use information technology and those who cannot" (Sipior, Ward \& Marzec, 1287). The data presented in the study is very telling about the current state of technological exposure in America as well in other countries, and how it correlates to a country's economic status or use or democracy. The main cause of the digital divide stems from a lack of social media use in other countries, specifically the internet. As companies diversify the way in which they market to their consumer bases through the use of social media, and individuals find more ways to interact through digital devices and social media platforms, traditional media forms evolve through a process known as remediation and it is this process which fuels the digital divide.

Many emerging popular brands attain marketable status within new media due to remediation, which serves as a perfect example of what social media is doing to traditional 


\section{هبلة الخدهة الاجتهاعية}

media. Remediation is not actually a form of replacing but it's more a form of convergence. Bolter and Grusin note that, "remediation is the process by which new media encompasses, superimposes upon, and supersedes the modalities of the old media it seeks to overtake or replace. This is not to say that the old media will disappear, but it will take on new forms to adapt to the demands of the new technologies available to it" (Bolter \& Grusin, 20). Examples of remediation imposed on old media by new media can be seen with the success of corporations like Netflix, Hulu, Pandora, and Spotify all of which provide entertainment tools either through video or music in ways that are overshadowing and directly competing with convergence of technologies and of industries in production, development and distribution of Media convergence is not simply just a technological shift, but an altering of the relationship shared between, "existing technologies, industries, markets, genres, and audiences" (Jenkins, 26). Convergence alters the logic by which media industries operate and by which media consumers process news and entertainment (Jenkins, 26). In areas where it is common for people to have their own internet connection, remediation and media convergence are drastically changing the landscape in how people interact and gain information. The transfer of information through new social media and the use of digital devices is also creating a massive digital divide in areas that have yet to $b$ exposed to new technology.

As Meng-chun and Gee San assess in their cases study on bridging the global digital divide, "differing from previous studies that look at the Internet's popularity, this paper focuses on the speed of diffusion of such technologies over the period from 1997 to 2002 in order to highlight its role as a critical driving force in enhancing the social learning of a country" (Mengchun \& Gee San 308). This data is key at helping to identify not only how technologically deprived countries can enhance their capabilities, but also serves as a great tool for tracking the cause for how internet based telecommunications have been able to exponentially lap the countries that were left behind and reliant solely on traditional media. U.S. communication channels has increased since the Social Network media platforms has grown using email, cell phones, Skype, video conferencing, IPhones, Nooks. The core fining of Meng-chun and Gee San's study is that their empirical results show that a country with better social learning can harmonize its heterogenous populations, promote the sharing of knowledge as a result of using such technologies, and finally speed up the rate information technology diffusion (Meng-chun \& Gee San 307). No region of the world better reinforces this finding than the United States, as 


\section{هجلة الذدهة الاجتهاعية}

U.S. internet capabilities and online communities are using every form of media driven technologies exponentially. U.S. social networking is creating a real-time platform with additional features such as voting, surveys, consumer contact campaigns to name a few. Social networks are providing a plethora of way for consumers to communicate on the information highway. Some consider virtual communities as group of people sharing ideals and information, as old channels of communication lack the ability to communicate uniformly, according to the consumer's wants and needs. Much of the following research suggests that U.S. internet users are gradually evolving into social media addicts, especially since social networks accounted for

one third of the time spent online in the country in August (McDermott 23). The U.S. populations have such a significant increase in users, increase in usage time online and increase in U.S. Internet buyers.

In sum, traditional media is most commonly defined as newspaper, television, radio, magazines, newsletters, tax press and a wide range of other print publications, while social media is recognized as the new generation of communication technologies usually composed of digital, computerized, or network information mediums. The new resources provide by social media and driven by the digital age, empower businesses to engage consumers on a more personal level and to function more efficiently through online networks using cloud technology. Social media also empower citizens to take a more participatory role int their political systems and it forces them tot take an active role in staying informed. The impact social media has had on the society and stark contrasts. 


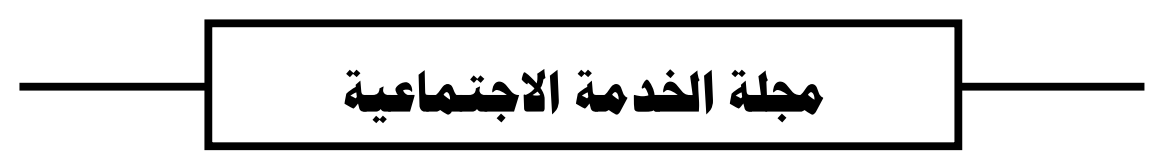

\section{Social Media Vs Traditional Media Print Journalism \& News Media}


Social Media vs. Traditional Media: Print Journalism \& News Media Looking at the declining print media and news media and the difference between traditional media's relationships with modern news and the newly established relationship it shares with social media, a basic understanding that a relationships exists between social networking and sense of belonging is evident in literature, demonstrating that relationships as being important to the well being for men and women (Brown, 2012). The social networking is a place for men and women to feel a sense of belonging to a group such as the social networks like Twitter and Facebook. The social aspect has enter the news, movies, political, business and personal platforms from a psychological standpoint of having the need to check the email to see what news or new friend has joined their network. The social network is an addicting relationship that each person that has a social networking account feels compelled to build a relationship with friends as well as new subscribers joining the groups with the same interest or ideas. An article published in the Public Sector Innovation Journal on the impact of New Media on Traditional Mainstream Mass Media notes that new media poses a challenge to traditional media, specifically in regards to the circulation of print newspapers in the U.S. The study looks at the affect social media has had on print news media in Malaysia noting that the influence has yet to prevent print news media outlets from generating sufficient ad-revenues and the model serves as a prime example that print media will be able to survive the popularity of social media in the U.S. he authors note that, "Even if there is a drop in circulation, it would be because the younger generation prefer the new media as they are more interactive compared to the online version of mainstream. There are also television stations which have an online presence such as TV3 and its owner, Media Prima" (Salman, Ibrahim, HJAbdullah, Mustaffa, \& Mahbob 2). He thesis argument of their report is that despite ample rise in social media as a news alternative, both mediums actually reinforce the use of one another. The main impact the authors suggest social media has had on print news journalism is that it has forced he print new market into an economic squeeze, which they argue, "could be its worst financial crisis since the Great Depression (Salman, Ibrahim HjAbdullah, Mustaffa, \& Mahbob 2)." This is due to the fact that advertising revenues are tumbling in response to reader habits favoring the free news sources provided by the internet. The authors point to the fact that many major news publications which have been burdened by massive debt loads, are laying off reporters and editors and declaring bankruptcy, shutting down completely or turning into web-only publications. Social media has also changed the way traditional print 
news publication circulate their content, the authors note that, Since 1999, almost $90 \%$ of daily newspapers in the United States have been actively using online technologies to search for articles and most of them also create their own news websites to reach new markets (Salman, Ibrahim, HjAbdullah, Mustaffa, \& Mahbob 2). U.S.'s social media statistics reached a great milestone last year. The Facebook U.S. consumers are reaching record numbers with the Facebook platform. The Facebook users have exceeded 12 million in U.S. since December 2010 and the U.S. Twitter users have exceeded 470,000 in October 2010. Today, U.S. has over 1 million users of Facebook in U.S. (TechinAsia). Friendster said there are 2.2 million active U.S. users on its social network. Despite this authors note that, "the long-term picture of new media or mass media information flows is not easy to predict. Mass media news outlets are struggling with changing gate-keeping standards due to demands for interactive content produced by audiences themselves. Ordinary citizens are empowered to report on their political experiences while being held to high standards of information quality and community values. In the long run, these tendencies may be the most revolutionary aspects of the new media environment (Salman, Ibrahim, HjAbdullah, Mustaffa, \& Mahbob 3).” In December 2008, Twitter Facts estimated a total of 3,429 Twitter users in U.S. TwitDir have a total of 4,013,391 accounts and 2,231 of them with 'U.S.' within their location detail (Hui, 2). Active digital consumers in U.S. predominantly use Facebook, according to the above metric. It also shows that Blogger and YouTube are more popular in Malasyia then Twitter among active digital consumers.

In analyzing key distinctions between traditional mainstream mass media and new alternative media, the authors note that mass media is heavily centralized, requires ample investment and the resources utilized by mass media outlets which allow them to function can be significantly influenced by the government. New alternative media differs from traditional mass media in that it's decentralized, does not require significant investment while providing interactivity among users and encouraging the participation of the public. The authors also note that new media is much harder for the government to regulate and control. This largely attributes to the popularity of new media in society. The challenge this poses conventional news media stems not just from the ease of use presented by alternative media, but as he authors note, "some observers believe that the challenge faced by conventional media, especially newspapers, has to do with the perfect storm of the global economic crisis, dwindling readership and advertising dollars, and the inability of newspapers to monetize their online efforts" (Salman, 


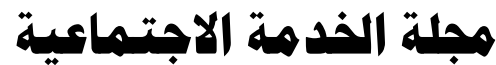

Ibrahim, hJaBDULLAH, Mustaffa, \& Mahbob 3). The way the global economic crisis played a part in alternative media taking over a 'lion-share' of media ad- revenue, was through the depressed economy making it necessary for businesses o cut their advertising budgets. This led to widespread cost-cutting measurements that resulted in the closure of print newspapers, bankruptcy and job cuts. The authors note this setback has led many major news giants to point their finger at Google as the major culprit causing the decline in print media.

The authors note that accusations of copyright infringement have been directed towards Google by publishers like Sir David Bell, who argued that Google and Yahoo of stole the contents of newspapers. They also mention allegations issued by media mogul Rupert Murdoch in early April 2009, who asked "should we be allowing Google to steal all our copyrights?" (Salman, Ibrahim, HjAbdullah, Mustaffa, \& Mahbob 3) Finally, Sam Zell, the owner of the Tribune Company, which is responsible for publications like the Chicago Tribune, the Los Angeles Times and the Baltimore Sun, noted that "it was the newspapers in America which allowed Google to steal their contents for nothing, but asked without the contents what would Google do, and how profitable would Google be?" (Salman, Ibrahim, HjAbdullah, Mustaffa, \& Mahbob 4) Much of this conflict reinforces the notion that alternative media has brought about drastic changes, dramatically changing the status quo and foundation on which news was traditionally produced and distributed. In their defense the Google founders argued that Google News intentionally only shows the headlines of stores, then providing a link to the actual news site which they argue increases traffic to the online version of the publication. In this respect the search engine is providing a service to traditional news outlets that venture to have an online presence. Despite this, it's noted, according to the Audit Bureau of circulations, that in 2008 U.S. newspapers saw a 7\% decline in daily circulation which carried over into 2009.

A large majority of the readership of traditional media outlets, are now getting their news from sites like Facebook and Youtube, as authors note that, "in addition to the so-called stealing of contents in the US, for example, advertising dollars were not forth coming due to the squeeze by the economic slowdown. Newspapers have also lost much of their classified advertisement to the Internet (Salman, Ibrahim, HjAbdullah, Mustaffa, \& Mahobob 5)." There are many factors that determine the buyer habits, however, the available research found the number of Internet users versus the Internet buyers that may have some significance in providing some answers on 
the buying habits of U.S. online consumers. Interestingly, in U.S., Facebook is the first most watched content site while in emerging markets like Malaysia, Facebook is listed as the country's second most watched video content site. Though YouTube occupied the top spot with almost 9 million unique visitors from the country, Facebook notched 4.1 million video viewers which are impressive considering it is not a video specialist (Russel, 2). This demonstrates how social media is being used as a sound tool for global expansion for many businesses into international markets. It will be interesting to observe how Face book viewing progresses in Asia where the social network continues to grow steadily. Coupled with growing access from mobile devices, social media in U.S. is vastly becoming the sole avenue for media related content and its video sharing content over the platform at increasing rates (Russel, 1).

The Nielsen literature provides a body of research on social media data and other criteria that documents trends especially in regards to publishing. The Nielsen Social Media Social Networking Report 2007 provides some very clear and precise trends from several pints of views including various populations include in the studies such as England, Switzerland, U.S. and Germany. The literature is not biased and very accurate. It should be noted that, "newspapers in the US cited huge losses. The Christian Science Monitor, for example, has lost about \$18.9 million per year forcing it to stop printing daily and, instead, printing only weekly editions" (Salman, Ibrahim, HjAbdullah, Mustaffa, \& Mahbob 5). The Nielsen report support the fact that social networking is more effective than word of mouth WOM or traditional print publishing, and this is a prime example of why publications like the Christian Science Monitor. Furthermore authors note that, "The Rocky mountain News in Denver published its last print edition on April 3, 2009 after 149 years of publication as it was losing \$1.5 million a month (Nielsen). The US Bureau of Labor Statistics showed that newspapers cut nearly 50,000 jobs-roughly 15 percent of the industry's work force-between June 2008 and June 2009 (The Star Online, September 2009)" (Salman, Ibrahim, HjAbdullah, Mustaffa, \& Mahbob 5). The Nielsen reports all support the fact that social networking is more effective that WOM or traditional publishing; the uniqueness of the Nielsen literature is based on the fact they have been presenting these type of reports for years for the United States but now they present information that is based on the how the whole world is impacted by social networking, as well as other internet based media entities. 
The Nielsen literature provided data from the last 5 years while pulling all available Social Networking statistics into one report. This literature gives the paper credence because no other organization has collected as much real data and in real time. The numbers are not manipulated, which Nielsen goes to extreme measures and cross checks to ensure they have the best accumulation of social networking data in the world. The literature provides an unexpected static that is believed no other research has accumulated in one place. The report provides exactly how many minutes the consumers spend shopping online. This information is invaluable to any research concerning social networking because the numbers can now be broken down to the smallest denominator, which validates the data. The same report provides the same data for minute's usage by digital, music, books, DVD's and video games. The popularity of using social media as a platform for advertising can be directly connected to the close proximity online ads have on social networks with their online stores and the ability of friends and followers to make a direct purchase. This ad revenue can be seen influencing the traditional news media industry by replacing its market share in the news media industry by replacing its market share in the news media industry. Authors note that, "Newspapers in the US cited huge losses. The Christian Science Monitor, for example, has lost about \$18.9 million per year forcing it to stop printing daily and, instead, printing only weekly editions. The Rocky Mountain News in Denver published its last print edition on April 3, 2009 after 149 years of publication as it was losing \$1.5 million a month" (Salman, Ibrahim HjAbdullah, Mustaffa, \& Mahbob 6). These losses in earnings by the news outlets are direct result businesses seeking social media outlets for advertising. The authors further note that, "The US Bureau of Labor Statistics showed that newspapers cut nearly 50,000 jobs roughly 15 percent of the industry's work force between June 2008 and June 2009" (Salman, Ibrahim, HjAbdullah, Mustaffa, \& Mahbob 5). These losses can be directly attributed to the success of sites like Facebook ad the ability of users to utilize the news feeds of their friends and fan pages as a way to stay informed.

It should be noted that the newspapers industry is not completely removed from the competitive market. The authors do point out that some major publications that managed to establish an online presence and find value in alternative revenue building outside of traditional ad space, have managed to stay afloat and even find profits in the digital era. The authors note that, "despite the bad times, however, there are some successful stories involving newspapers which have been able to weather the storm and remain resilient through their online digital 


\section{هبلة الخدهة الاجتهاعية}

newspapers" (Salman, Ibrahim, HjAbdullah, Mustaffa, \& Mahbob 5). The specific publications the authors mention that have been able to stay afloat and even find success in this new digital market share arena for news journalism while other publications are being shut down, include, “companies like The New York Times, Knight Ridder, and the Washington Post. The New York Times has been a real leader on consumer demographic marketing which is very telling as consumer demographic marketing is the main aspects of Facebook advertising and most online ad models like Google ad-words thrive on. The authors note that, "with 16 million registered users, nytimes.com is one of the only media sources that can let you customize an advertising message with specific demographic cuts e.g. male users over fifty reading the sport section. They collect only five categories of consumer demographic data: age, sex, income, geography and e-mail. Through this method, The New York Times has been able to request 70\% premiums for their demographically targeted advertising (Salman, Ibrahim, HjAbdullah, Mustaffa, \& Mahbob 5). This suggests that the market is available for those willing publications willing to relocated to a web-based platform. In respect to the impact that social media has made on the news journalism industry, it's clear that 'print only news' is no longer a workable business model.

The success of the online news market can largely be attributed to the fact that nearly $75 \%$ of the U.S. population is made up of internet users. It's noted that, "the U.S. has the second largest Internet user population in the world with 227.7 million users trailing only behind China. In terms of the percentage of population or penetration of internet users, the US has 74.1\% (Internet World Stats, 2009)" (Salman, Ibrahim, HjAbdullah, Mustaffa, \& Mahbob 5). With numbers like this, it's understandable why people would not be able to pass up the convenience of free news available online.

In sum, data makes it very clear that Facebook has changed how individuals get their news. The Facebook platform is one the most active social networking platforms on the Internet with plenty of competition with Twitter. However, these virtual entities also work simultaneously. Facebook is a type of WOM vehicle but it is taking it to another level with notoriety whether if it is a conversation at work or chatting with friends, the general concept of social networking is always adding friends and sharing your personal interest with each other. Facebook is approaching 80 million members and with sign-ups at an insane pace of 2 million 


\section{هبلة الخدهة الاجتهاعية}

weekly (Bulik, 1). The digital world of Social Networking is evolving every day creating a new way consumers can find goods and services that cater to their specific profiles. The online industry is trying to determine which is the better driving force between the already proven WOM or social network platforms. The social revolution has begun with the new membership technology that tracks a personal likes and dislikes on social networking platforms. The social networking marketing methods always target consumers that have the highest usage levels. This leads to the success of membership based social networking. The social network has the real time data on when they sign on, what they buy what offers they turn down and when they like to shop. All this information is saved in real-time and it refreshes each time the consumer refreshes their screen based on their tendencies. The real genius of Twitter an Facebook is they are able to consistently create a viral buzz for all their current and potential new customers using many different referral methods or gifts methods. The members get discounts and special gifts for referring a friend to the social network. This means the social networks are the best at presenting their products and goods brands to the teenagers, children, and adults. The online businesses are following the leaders by spending more revenues for Internet marketing efforts that will improve the quarterly sales numbers. It is fascinating to note how Facebook rose to this level, surpassing media power by web giants Google and Yahoo. In the last one year, Facebook grew 34 percent with a total number of profiles to 130 million, making itself a high visibility website for brands to advertise (McDermott, 22). The new model fo advertising and marketing is building social network communities, providing all the essential guidelines for novice users to spend all of their time in a specific network site that provides all the available applications they need. 


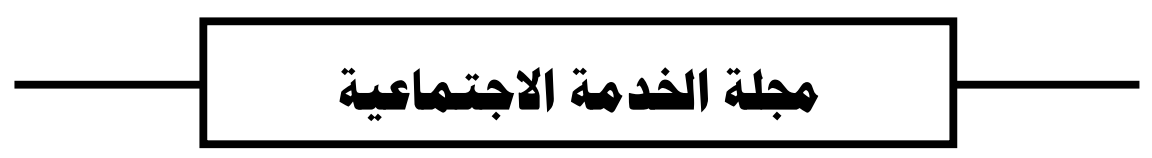

Work Cited

Bennett, W. L. 2003. "New Media Power: The Internet and Global Activism.” Pp. $17-37$

in Contesting Media Power: Alternative Media Power in a Networked World, edited by

N. Couldry \& J. Curran. Lanham, MD: Rowman and Littlefield.

Brown, M. (2012).Social networking and individual performance:

examining predictors of participation." Old Dominion university, 2011. United States - Virginia:ProQuest Dissertations \& Theses (PQDT)

Bulik, B. "How Facebook is like word-of-mouth marketing on steroids." 2006. Web. 19 Jun. 2013.

Creeber, G. \& R. Martin. 2009. Digital Cultures: Understanding New Media. Berkshire, England: McGraw-Hill.

Hui, Lim Yung. "Social Media Marketing and U.S.â€ $€^{\mathrm{TM}_{S}}$ Biggest Brands."GreyReviewcom.

N.p., 20 Oct. 2008. Web. 15 Jan. 2013. <http://www.greyreview.com/2008/10/20/social- media-marketing-and-U.S.sbiggest-brands/>.

Jenkins, Henry. Convergence Culture: Where Old and New Media Collide. NYU Press, 2008. 336. Print. McDermott, I. (2006). I need Facebook. Searcher, Vol. 14 Issue 4, p22-25, 4p, 3bw 


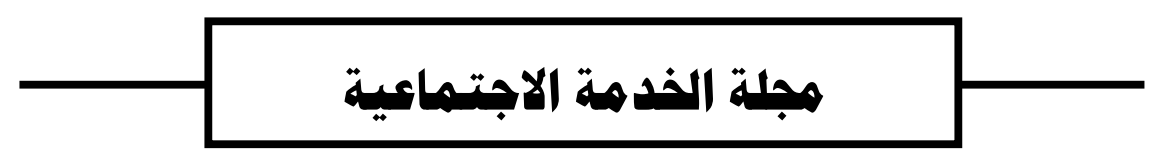

Meng-chun Liu \& Gee San, "Social Learning and Digital Divides: A Case Study of Internet

Technology Diffusion,” Kyklos, Wiley Blackwell, vol. 59(2), pages 307321, 2006.

McDermott, I. (2006). I need Facebook. Searcher, Vol. 14 Issue 4, p22-25, 4p, 3bw

Nielsen. (2012). Social media social networkingreport 2007. Retrieved from www.neilsen.com

Nielsen. (2012). Social media social networkingreport 2008. Retrieved from $\underline{\text { www.neilsen.com }}$

Nielsen. (2012). Social media social networking report 2010. Retrieved from $\underline{\text { www.neilsen.com }}$

Nielsen. (2012). Social media social networking report 2011. Retrieved from $\underline{\text { www.neilsen.com }}$

Nielsen. (2012). Social media Social networkingreport 2012. Retrieved from www.neilsen.com

Nielsen. (2012).Social networking report 2007. Retrieved from www.nielsen.com

Nielsen. (2012). South-East-Asia. Southeast Asian digital consumer habits and trends. 


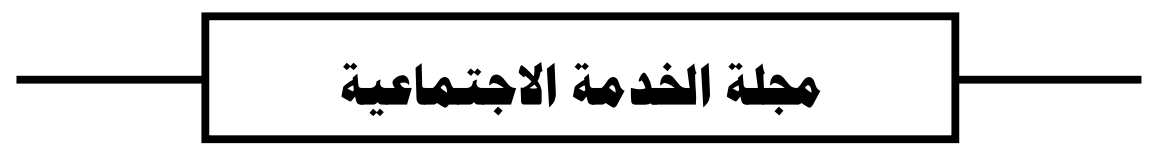

Retrieved from http://www.nielsen.com/us/en/insights/reportsdownloads/2011/south- east-asian-digital-consumer-habits.html

Potashnik, M. “The International Gap In Technology - The Digital Divide In Education, Education and Technology In Balance.” Net Industries and Its Licensors. 2013

Russel, John. "Social media responsible for one third of web traffic in Malaysia" The Next

Web. 19 Jun. 2013

Salman, Ali, Faridah Ibrahim, Mohd Y. HjAbdullah, and Normah Mustaffa. "How Startup Funding

Works Http://shrd.by/onaPLa." The Innovation Journal: The Public Sector Innovation Journal 7th ser. 16.3 (2011): 1-11. Print

Sipior, C. Janice, Ward, Burke Marzec, Joanna. An Initiative to Narrow the Digital Divide:

Preliminary Results. "ECIS. 2002

TechinAsia.(2012). YouTube Launches Localized Service in U.S. http://www.techinasia.com/youtube-U.S./

Tiene, D. "Addressing the Global Digital Divide and its Impact on Education Opportunity."

International Council for Education Media. 2002. Web. 19 Jun. 2013 